\title{
PROPAGAÇÃO DA ESPIRRADEIRA POR MEIO DA TÉCNICA DA ALPORQUIA EM DIFERENTES SUBSTRATOS ${ }^{1}$
}

\author{
PROPAGATION OF THE Nerium oleander Linn. BY THE AIR-LAYERING \\ TECHNIQUE IN DIFFERENT SUBSTRATUM
}

\author{
Francisco Antonio MARÇALLO ${ }^{2}$ \\ Roberto Carlos de ALMEIDA ${ }^{3}$ \\ Kátia Christina ZUFFELLATO-RIBAS ${ }^{4}$
}

\begin{abstract}
RESUMO
A propagação vegetativa de plantas ornamentais é geralmente realizada por meio de estaquia. Entretanto, esse processo reprodutivo nem sempre apresenta resultado satisfatório, especialmente em épocas do ano em que a planta vive um intenso desenvolvimento vegetativo, interferindo assim na produção comercial. Outra técnica, também muito utilizada, é a alporquia. As informações necessárias para esta prática são poucas e inconsistentes. Para tanto torna-se indispensável adotar uma abordagem analítica e explicativa sobre esta técnica. Atualmente a alporquia em ornamentais vem se apresentando como um método de propagação que proporciona bom enraizamento e, muitas vezes, sem a necessidade da aplicação de fitoreguladores. Esse trabalho procurou avaliar a eficiência do processo de alporquia no enraizamento da espirradeira, em três diferentes substratos (serragem de Dicksonia sellowiana [xaxim]; vermiculita; e terra orgânica). O experimento foi instalado no Campus III, Centro Politécnico da Universidade Federal do Paraná, na cidade de Curitiba, no equinócio do ano 2000 , onde utilizou-se a técnica do anelamento completo em ramos semi-lenhosos de plantas adultas de espirradeira (Nerium oleander). Foi utilizado delineamento inteiramente casualizado e os dados submetidos à análise de variância, pelo Teste de Tukey ao nível de $1 \%$ de probabilidade estatística. Cada tratamento constou de quatro repetições, avaliadas após 63 dias da instalação do experimento. Concluiu-se que a prática da alporquia promoveu enraizamento suficiente em todos os substratos, sendo a terra orgânica aquela que propiciou maior desenvolvimento das raízes.
\end{abstract}

Palavras-chave: Nerium oleander, espirradeira, alporquia, propagação vegetativa.

\begin{abstract}
The vegetative propagation of ornamental plants is generally made by the cutting technique. However, this reproductive process not always presents satisfactory results, especially at times of the year when the plant lives an intensive vegetative development, this way affecting, its comercial production. Air-layering is another largely used technique. The necessary information for this practice is rare and inconsistent. So, it is indispensable to adapt an analitic and explanatory approach. Nowadays, the air-layering in ornamental plants has been represented as a propagation method that supplies a good rooting and many times, without the necessity of a phytoregulators application. This paper tried to avaluate the efficiency of the air-layering process related to the rooting of the Nerium oleander, in three different substratum (Dicksonia sellowiana [tree fern] sow dust, vermiculite, and organic soil). The experiment was installed at Campus III, Technological Center of the Universidade Federal of Paraná, in Curitiba city, in the equinox of the year 2000, where the complete ringing technique was used in semi-woody branches of adult plants of Nerium oleander. It was used completely randomized delineation and the data submieted to the variance analysis, by the Tukey Test to a level of $1 \%$ of statistic probability. Each treatment consisted of four replications, analysed after 63 days of the installation of the experiment. It was conclued that the air-layering practice promoted enough rooting in all substratum, and the organic soil the one that supplied the most development of the roots.
\end{abstract}

Key words: Nerium oleander, air-layering, vegetative propagation.

\footnotetext{
1 Trabalho apresentado na Disciplina de Fisiologia da Reprodução Vegetal, do Curso de Pós-Graduação em Agronomia, Produção Vegetal, Universidade Federal do Paraná.

2 Engenheiro Agrônomo, Mestrando no Curso de Pós-Graduação em Agronomia, Produção Vegetal da Universidade Federal do Paraná, Rua dos Funcionários, 1540 CEP80035-050 Curitiba-PR, agroword@agrarias.ufpr.br ڤautor para correspondência.

3 Engenheiro Agrônomo,M.Sc., Universidade Tuiuti do Paraná, Professor.

${ }^{4}$ Bióloga, Doutora, Universidade Federal do Paraná, Professora Adjunto.
} 


\section{INTRODUÇÃO}

A propagação de plantas ornamentais é geralmente realizada por meio de estaquia. Entretanto, este processo nem sempre apresenta resultado satisfatório, especialmente em épocas do ano em que a planta vive um intenso desenvolvimento vegetativo. Para algumas plantas a produção comercial torna-se comprometida devido a esse aspecto, necessitando-se a utilização de outras técnicas de propagação como a alporquia (Pacheco et al., 1998) [5].

A alporquia pode ser utilizada em diversas plantas, que tenham ramos lenhosos ou semilenhosos. É um processo bastante empregado, não requerendo a utilização de equipamentos especializados, reduzindo os custos da produção de novas plantas e não exigindo muitos cuidados, apenas os conhecimentos básicos para a sua execução (Lucchesi, 1993) [3].

A alporquia em frutíferas vem se apresentando como um método de multiplicação que proporciona bons resultados (Calderon, 1993) [1], especialmente para lichia (Litchi chinensis Sonner), espécie que é propagada quase que exclusivamente por este método (Galan, 1990) [2].

Em ornamentais existem muitas plantas nas quais obtém-se sucesso com a alporquia. Entre estas destacam-se: Codiaeum variegatum Blume, Hibiscus rosa-sinensis L., Bounganvillea spectabilis W., Cammelia japonica L., Schefflera actinophyla Harms., Polyscias filicifolia L., Stifftia chrysantha Mikan, Pittosporum sp., Ixora sp., Rhododendron $s p .$, Laurus nobilis L., Nerium oleander L. (Lucchesi, 1993) [3].

O objetivo deste trabalho foi avaliar a eficiência do processo de alporquia na multiplicação vegetativa da espirradeira (Nerium oleander L.) com relação ao seu enraizamento, em três diferentes substratos.

\section{METODOLOGIA}

Os alporques foram realizados no equinócio do ano 2000, em ramos semi-lenhosos de plantas adultas da espirradeira (Nerium oleander L.). As plantas encontram-se no Campus III, Centro Politécnico, da Universidade Federal do Paraná, em Curitiba, Paraná.

A metodologia do processo de alporquia tem sido descrito por numerosos autores citados por Galan, (1990) [2] e destaca-se a descrita por Lucchesi (1993) [3] que foi seguida neste trabalho.

Foram selecionados ramos com 1 a $1,5 \mathrm{~cm}$ de diâmetro, fazendo-se os alporques a uma distância aproximada de 40 a $50 \mathrm{~cm}$ abaixo do ápice dos mesmos. Foi empregada a técnica de anelamento completo para a realização das alporquias, com uso de um canivete comum.

Os tratamentos foram: T1 = substrato pó de xaxim; T2 = substrato vermiculita; e T3 = substrato terra orgânica (West Garden $\AA$ ). Os substratos previamente umedecidos envolveram a região anelada do ramo, cobertos com lâmina de polietileno sendo amarrados nas extremidades para sustentação do material e manutenção da umidade. Foi utilizado o delineamento inteiramente casualizado (DIC) e os dados submetidos à análise de variância pelo Teste de Tukey, a $1 \%$ de probabilidade estatística. Cada tratamento constou de quatro repetições, sendo realizados, ao todo, 12 alporques. A avaliação se deu 63 dias após a instalação do experimento. Os ramos foram removidos da planta matriz e levados para o laboratório sendo avaliado o número de alporques enraizados. Após a remoção e a pesagem da matéria fresca das raízes (MF), estas foram colocadas em estufa com temperatura constante de $90^{\circ} \mathrm{C}$, durante tempo suficiente para sua secagem e pesadas novamente para obtenção da matéria seca (MS).

\section{RESULTADOS E DISCUSSÃO}

Ocorreu a formação de raízes em todos os alporques analisados, resultando em 100\% de ramos enraizados, indicando que a espécie Nerium oleander apresenta fácil enraizamento, podendo ser propagada por alporquia. As raízes foram formadas tanto acima quanto abaixo da área exposta ao tratamento. Alguns ramos mostraram a formação de calo na parte superior da incisão, fato também observado por Pacheco et al. (1998) [5].

Foi observada diferença significativa entre os tratamentos para peso da MS das raízes, bem como para o peso da MF destas. Em relação ao peso da MS das raízes, T3 apresentou a maior média $(0,433 \mathrm{~g})$, seguido de T2 $(0,285 \mathrm{~g})$ e este por T1 $(0,240 \mathrm{~g})$ (Tabela ), sendo que os valores da MS variaram de 0,070 a $0,580 \mathrm{~g}$. Para a MF das raízes, T3 foi o tratamento que apresentou a maior média $(1,770 \mathrm{~g})$, seguido de T1 $(1,225 \mathrm{~g})$ e este por T2 $(0,980 \mathrm{~g})$ (Tabela 1$)$, sendo que os valores de MF variaram de 0,080 a $3,110 \mathrm{~g}$.

TABELA 1 - Valores médios de quatro repetições obtidos em Nerium oleander L. após 63 dias da realização das alporquias, Curitiba, PR, $2000^{1}$

\begin{tabular}{|c|c|c|}
\hline Tratamento & $\mathrm{MF}^{2}(\mathrm{~g})$ & $\mathrm{MS}^{3}(\mathrm{~g})$ \\
\hline T1 = Xaxim & 1,225 a & $0,240 \mathrm{a}$ \\
\hline T2 = Vermiculita & $0,980 \mathrm{~b}$ & $0,285 \mathrm{~b}$ \\
\hline T3 = Terra orgânica & $1,770 \mathrm{c}$ & $0,433 \mathrm{c}$ \\
\hline $\begin{array}{ll}1 & \text { Médias seguidas de } \\
& \text { Teste de Tukey a } 1 \% \\
2 & \text { Matéria fresca da raiz } \\
3 & \text { Matéria seca da raiz }\end{array}$ & $\begin{array}{l}\text { não diferer } \\
\text { ade }\end{array}$ & entre si, $p$ \\
\hline
\end{tabular}

Os resultados diferenciados (Tabela 2) dos tratamentos indicam, possivelmente, que diferentes combinações entre auxinas e cofatores do enraizamento, estimulados pelo suprimento constante de elementos minerais (Mielke et al., 
1994) [4] tenham sido as causas das variações ocorridas na emissão e desenvolvimento de raízes nas diferentes plantas utilizadas, assim como do sucesso obtido com a utilização desta técnica sem a necessidade do emprego de promotores do enraizamento. Então sugere-se, para minimizar o coeficiente de variação (Tabela 2), a utilização de maior número de alporques por tratamento em um próximo trabalho.

TABELA 2 - Resultados da análise de variância obtidos em Nerium oleander L. após 63 dias da realização das alporquias, Curitiba, PR, 2000

\begin{tabular}{lrrcc}
\hline \multicolumn{1}{c}{$\mathrm{FV}^{1}$} & $\mathrm{GL}^{2}$ & $\mathrm{QM}^{3}$ & $\mathrm{~F}^{4}$ & $\mathrm{CV}^{5}(\%)$ \\
Tratamentos & 2 & 16,535 & $24,68^{* *}$ & 88 \\
Erro & 9 & 0,670 & - & - \\
\hline Total & 11 & - & - & - \\
\hline 1 & Fator de variação & ${ }^{2}$ Graus de liberdade & \\
${ }^{3}$ Quadrados médios & ${ }^{4}$ Teste de Fisher \\
5 & Coeficiente de variação \\
** Diferenças significativas a 1\% de probabilidade pelo Teste de \\
Tukey
\end{tabular}

\section{CONCLUSÕES}

1) A eficiência do processo de alporquia na propagação vegetativa da espirradeira (Nerium oleander L.) é excelente.
2) O substrato terra orgânica é mais efetivo que os outros substratos utilizados.

\section{REFERÊNCIAS}

[1] CALDERON, E. A. Fruticultura general. 3.ed. México: Grupo Noriega Editores, 1993. $763 \mathrm{p}$.

[2] GALAN, V. S. Los frutales tropicales en los subtropicos. Madri: Ediciones Mundi-Prensa, 1990. $133 \mathrm{p}$.

[3] LUCCHESI, A. A. Propagação de plantas através da alporquia. Piracicaba: USP / Centro de Energia Nuclear na Agricultura - CENA/ESALQ, $1993.8 \mathrm{p}$. (Informativo Técnico 13).

[4] MIELKE, M. S.; FACHINELLO, J. C.; NACHTIGAL, J. C.; MATIUZ, B.; ENDRES, L.; GOMES DOS SANTOS FILHO, B. Comportamento fisiológico de goiabeira serrana quando multiplicada por mergulhia de cepa. Scientia Agricola, Piracicaba, v.51, n.1, p. 21-27, 1994.

[5] PACHECO, A.. C.; CASTRO, P. R. C.; APPEZZATO DA GLÓRIA, B. Aspectos anatômicos do enraizamento da videira muscadínia (Vitis rotundifolia Michx.) através de alporquia. Scientia Agricola, Piracicaba, v.55, n.2, p. 210-217, 1998.

Recebido para publicação em 05 JUN 2001 [SA 048/2001] Aceito para publicação em 14 SET 2001 